\title{
A CRISE DA TAXA MINERÁRIA PERANTE O STF E AS CONSEQUÊNCIAS PARA O
} ESTADO DO PARÁ.

\author{
Vitória Mota Zocatelli ${ }^{1}$ \\ Lise Tupiassú*
}

\section{RESUMO}

Neste trabalho, discute-se a crise da taxa minerária perante o STF e as consequências para o Estado do Pará. O objetivo foi averiguar a crise da taxa minerária perante o STF e as consequências para o Estado do Pará, diante de sua possível inconstitucionalidade. Concluiuse que, diante de uma possível declaração de inconstitucionalidade da Taxa Minerária do Pará, o Estado terá seu orçamento diretamente impactado, e será impactada a fiscalização da atividade que é financiada pela referida taxa. Utiliza-se o método hipotético dedutivo, através de pesquisa bibliográfica, mediante estudo de doutrinadores.

Palavras-chaves: Atividade minerária. Fiscalização. Poder de polícia. Tributação. Taxa de Controle, Monitoramento e Fiscalização das Atividades de Pesquisa, Lavra, Exploração e Aproveitamento de Recursos Minerários.

\section{THE MINING RATE CRISIS BEFORE THE STF AND THE CONSEQUENCES FOR THE STATE OF PARÁ.}

\begin{abstract}
This paper discusses the mining tax crisis before the STF and the consequences for the State of Pará. The objective was to investigate the mining tax crisis before the STF and the consequences for the State of Pará, given its possible unconstitutionality. It was concluded that, in view of a possible declaration of unconstitutionality of the Pará Mining Tax, the State will have its budget directly impacted, and the inspection of the activity financed by that tax will be impacted. The deductive hypothetical method is used, through bibliographical research, through the study of indoctrinators.
\end{abstract}

Keywords: Minig activity. Supervision. Police power. Taxation. Rate of Control, Monitoring and Supervision of Research Activities, Mining, Exploration and Exploitation of Mining Resources.

\section{INTRODUÇÃO}

\footnotetext{
${ }^{1}$ Mestranda em Direito, Políticas Públicas e Desenvolvimento Regionais no Programa de Pós Graduação do CESUPA. Graduada em Direito pelo Centro Universitário do Pará - CESUPA. E-mail: vitoriamotazocateli@hotmail.com

** Doutora em Direito Público pela Université Toulouse 1 - Capitole. Mestre em Direito Tributário pela Université Paris I - Panthéon-Sorbonne. Mestre em Instituições jurídico-políticas pela Universidade Federal do Pará. Mestre em Direito Público pela Université de Toulouse I - Capitole. Procuradora Federal. E-mail: lise@ufpa.br
} 
A humanidade exerce a atividade extrativista dos minérios há muitos anos e é indubitável que a operação para tal é uma das mais ambientalmente destrutivas. Isso decorre das consequências da atividade, que são a modificação de grandes áreas e a alta produção de resíduos que é gerada, além da relevante característica da finitude dos minérios.

Por seguinte, tornou-se aceita a ideia de que as empresas exploradoras de minérios possuem responsabilidades de gerenciar e reabilitar os locais das minas, durante e após o período de exploração. Visto desse modo, os Estados possuem, por consequência, o dever de fiscalizar e resguardar os direitos das comunidades que nestes locais habitam. Nesse sentido, o Poder de Polícia se mostra pertinente no âmbito da atuação preventiva do Estado, visto que, compreende as medidas relativas à segurança das estruturas, e, neste caso, das mineradoras.

Enquanto atividade desenvolvida pela Administração Pública, o Poder de Polícia encontra fundamento nos art. 77 e 78 do Código Tributário Nacional - CTN e no art. 145, II, da Constituição Federal, que autoriza o Poder Público a exigir do interessado o pagamento de taxa, isto é, uma contraprestação do particular para com o Estado, diante do serviço prestado pela Administração.

Por consequência, em 2011, o Estado do Pará, um dos maiores estados mineradores do Brasil, criou a Taxa de Fiscalização de Recursos Minerários (TFRM). O recolhimento da TFRM é importante, visto que, recai sobre a extração mineral que gera externalidades socioambientais negativas, demandando que a ação do Estado considere não apenas os custos internos da atividade fiscalizatória, mas especialmente a necessidade de promoção da internalização dos custos externos gerados pela atividade.

Ocorre que, foi apreciada pelo Supremo Tribunal Federal - STF uma Ação Direta de Inconstitucionalidade - ADI número 4.786, ajuizada pela Confederação Nacional das Indústrias - CNI em 2012, alegando que a referida taxa gera arrecadação exorbitante em relação à atuação estatal.

A questão que guia esse estudo pode ser assim formulada: Em que medida a possível declaração de inconstitucionalidade da Taxa Minerária afetaria o Estado do Pará?

Para responder a este questionamento, este trabalho tem como objetivo geral averiguar a crise da taxa minerária perante o STF e as consequências para o Estado do Pará. E como objetivos específicos analisar a cobrança da TFRM no Estado do Pará como estratégia de obtenção de recursos, apontar como se deu a ADI 4.786 sobre a Lei $n^{\text {o }} 7.591 / 11$ e 
descrever os possíveis reflexos de uma eventual inconstitucionalidade da taxa minerária no Estado do Pará.

Para responder a problemática proposta e alcançar os objetivos delimitados, este trabalho utilizou a metodologia hipotético dedutiva, por meio da técnica de pesquisa bibliográfica, se valendo de doutrinadores e tendo como principais referenciais o artigo de Philip Andrews-Speed e Christopher D. Rogers, nomeado de Mining taxation issues for the future, que aborda sobre as questões de mineração e de tributação voltadas para o futuro, e o de Fernanda da Silva, que aborda sobre a complexidade da eficaz fiscalização e poder de polícia na atividade minerária. Além disso, realizou-se pesquisa de dados, utilizando a legislação estadual para analisar o orçamento público referente ao ano de 2021.

Buscar-se-à resposta ao problema supracitado com um trabalho desenvolvido em três capítulos. Primeiramente, serão apresentados aspectos conceituais sobre a Taxa de Fiscalização de Recursos Minerários (TRFM), a sua aplicabilidade na legislação brasileira e a falta de mecanismos tributários ao alcance do Estado para atrair riquezas para o Pará.

Secundariamente, será abordada a Ação Direita de Inconstitucionalidade - ADI $\mathrm{n}^{\circ}$ 4.786, que busca a declarar a inconstitucionalidade da Lei $\mathrm{n}^{\circ}$ 7.591/11, que instituiu a TRFM, os principais pontos de divergência que acarretaram a propositura da referida ADI e os julgamentos do Supremo Tribunal Federal que podem ser utilizados como precedentes favoráveis ou desfavoráveis à ADI.

E, por fim, no último capítulo, serão apresentadas as possíveis consequências geradas ao Estado do Pará a partir da decisão da ADI, por ser um Estado essencialmente exportador, atualmente a unidade da federação com maior volume de exportação de minérios, mas que ainda enfrenta dificuldades com povo com IDHM abaixo da média da região norte.

Por fim, nas conclusões será ofertada a reposta ao problema supra-apontado com base nas informações apresentadas ao longo do estudo.

\section{A COBRANÇA DA TAXA DE FISCALIZAÇÃO DE RECURSOS MINERÁRIOS (TFRM) NO PARÁ COMO ESTRATÉGIA PARA OBTENÇÃO DE RECURSO DIANTE DA AUSÊNCIA DE SUBSTÂNCIA TRIBUTÁRIA}

A exploração mineral ocorre há muitos anos e é inquestionável o quão ambientalmente destrutiva é tal operação, visto que, traz consigo a modificação de grande 
parte da paisagem onde a exploração ocorre e, consequentemente, uma alta produção de resíduos. Além da relevante característica da finitude dos minérios.

A Constituição Federal (BRASIL, 1988) dispõe em seu artigo 225, caput, que o direito ao meio ambiente ecologicamente equilibrado é um direito de todos, sendo bem de uso comum do povo e essencial à sadia qualidade de vida, impondo-se ao Poder Público e à coletividade o dever de defendê-lo e preservá-lo para as presentes e futuras gerações.

Diante disso e de grandes exemplos de desastres ocorridos por falta de fiscalização na atividade minerária, como o Caso Samarco ocorrido em Minas Gerais, faz necessária a presença do Estado através do poder de polícia na referida atividade e a sua relação com a complexidade da eficaz fiscalização.

Nesse sentido, é indubitável o dever do Estado de se orientar pelo interesse geral ou comunitário e pela aplicabilidade da justiça. Por seguinte, os estados mineradores brasileiros utilizam a competência material do art. 23, VI da Constituição Federal como justificativa para a instituição de Taxas de Controle e Fiscalização de Atividades Minerárias (TFRM), fundamentando-as na necessidade de remunerar o Poder de Polícia exercido pelo ente subnacional em tal esfera.

De acordo com Carvalho Filho (2006, p. 64), a expressão "poder de polícia” possui dois sentidos, um amplo e um restrito. O sentido amplo, refere-se a toda e qualquer ação restritiva do Estado em relação aos direitos individuais. O sentido estrito, configura-se como atividade que confere aos agentes da Administração restringir e condicionar a liberdade e a propriedade.

Meirelles (2001, p.123) considera tal atividade como "a faculdade de que dispõe a Administração Pública para condicionar e restringir o uso e gozo de bens, atividades e direitos individuais, em benefício da coletividade ou do próprio Estado".

Nesse diapasão, em 2011, os estados do Amapá, Pará e Minas Gerais criaram a Taxa de Fiscalização de Recursos Minerários (TFRM), uma espécie de tributo sobre a mineração, por meio de leis estaduais. O fundamento constitucional utilizado foi o disposto no art. 23, XI da $\mathrm{CF} / 88$, que trata da competência comum de todos os entes federados, e traz a atribuição para registrar, acompanhar e fiscalizar as concessões de direitos de pesquisa e exploração mineral em seus territórios (BRASIL, 1988).

No momento de sua criação, os três diplomas legais muito se pareceram em relação ao fato tributado (tonelada de minério extraído), o valor cobrado (uma ou três unidades fiscais 
por tonelada) e a justificativa de cobrança (exercício de fiscalização e regulação sobre a atividade minerária).

Sabe-se que, diferente dos impostos, que custeiam a máquina estatal de modo amplo e desvinculado, isto é, não específico a uma atividade, as taxas são pautadas no caráter retributivo. Desse modo, para que se possa exigir o pagamento da taxa, é necessária a realização de uma ação do Estado direcionada especificamente ao contribuinte.

O Código Tributário Nacional (CTN), em seu artigo 77, afirma que as taxas têm como fato gerador o exercício do poder de polícia ou o fornecimento de serviços públicos específicos e divisíveis a determinados beneficiários. Assim, percebe-se que as taxas possuem destinação certa, elas financiam a atuação do Estado prestada ao contribuinte.

Diante disso, deve ser analisado o princípio da equivalência na cobrança da taxa, de modo que, deve haver a vinculação entre o preço pago pelo contribuinte e o custo da atividade prestada pelo Estado, da qual decorre a cobrança do tributo.

A equivalência também concerne à ideia de que o gasto estatal se refere a um contribuinte, diante disso, não pode ser exigido que a toda a coletividade o suporte (SCHOUERI, 2019).

A legislação estadual que institui a referida taxa no Pará é a Lei no 7.591 de 2011, define como fato gerador da taxa o exercício regular do poder de polícia conferido ao Estado sobre a atividade de pesquisa, lavra, exploração e aproveitamento, realizada no Estado, dos recursos minerários. E estabelece como contribuinte da TFRM a pessoa, física ou jurídica, autorizada a realizar a pesquisa, a lavra, a exploração ou o aproveitamento de recursos minerários no Estado.

A lei isenta do pagamento da taxa minerária apenas o microempreendedor individual, a microempresa e a pequena empresa. E confere ao Poder Executivo a faculdade de reduzir a TFRM com o fim de evitar a onerosidade excessiva e para atender peculiaridades inerentes às diversidades do setor minerário.

No Pará, a mineração é um dos setores fundamentais da matriz econômica local, estando localizada uma das maiores minas de minério de ferro à céu aberto do mundo (ENRIQUEZ et. al, 2018, p. 06). Ocorre que, a exploração mineral evidencia a dicotomia de regiões que, apesar de ricas em recursos naturais, concentram altos índices de pobreza e desigualdade. 
De acordo com Daniel Athias (2020, p. 47), a exploração mineral é uma indústria base para toda a economia, que serve de insumo à cadeia de inúmeras outras indústrias e não se destina apenas à oferta de bens necessários para a prática dos direitos fundamentais, mas também para a satisfação dos novos patamares de bem-estar da sociedade.

Diante disso, resta evidente que os ativos naturais são imprescindíveis para os processos produtivos, e possuir essa vasta riqueza natural pode ser um meio de alavancar a economia para o alcance do desenvolvimento socioeconômico sustentável.

Murílio Monteiro (2005, p. 200) afirma que ter a arrecadação tributária como uma valorização dos recursos minerais, poderia trazer repercussões para o desenvolvimento regional.

Nesse sentido, os instrumentos tributários são necessários para que se possa aproveitar o 'boom mineral' e gerar desenvolvimento sustentável nessas regiões, dado que os recursos minerais são exauríveis e muitos locais ainda são dependentes dele.

Neste sentido reitera da Silva (2017, p. 64):

A estruturação de um sistema tributário holístico é instrumento importante para combater a maldição dos recursos minerais, na tentativa de não apenas tributar a dotação de riqueza no solo nacional, mas de fazer frente à dificuldade de aumentar a capacidade de valoração desses recursos. Em larga medida, os vários fatores elencados como causas da maldição esbarram, em alguma medida, nas principais funções do sistema tributário.

Nesse sentindo, percebe-se a importância do sistema tributário para gerar riquezas em valores que contribuam para o progresso. Ocorre que, atualmente, no Pará, faltam mecanismos tributários ao alcance do Estado para atrair tais riquezas, colidindo, diretamente, com o direito ao desenvolvimento.

O desenvolvimento é um direito humano inalienável, conforme dispõe o artigo $1^{\circ}$ da Declaração sobre o Direito ao Desenvolvimento da Organização das Nações Unidas (ONU), que destaca a pessoa humana no centro desse processo, devendo participar dos resultados alcançados em termos econômicos, culturais, sociais e políticos.

Diante disso, resta evidente que se faz necessário ter um Estado ativo, que busque solucionar os problemas decorrente de uma atividade tão importante, além de criar mecanismos indutores para regularizar como a atividade mineradora deve contribuir para tanto.

Nesse sentindo, e diante do supracitado poder de polícia exercido pelo Pará, através da legislação que instituiu a TFRM, o Estado afirma que a incidência da taxa em questão se 
dá em unidades padrão fiscais do estado (UPFPA), vigente na data do pagamento, por tonelada de minério extraído.

Ocorre que, em março de 2021, o Governo do Estado do Pará, a partir do decreto ${ }^{\circ}$ 1.353 alterou o decreto $\mathrm{n}^{\mathrm{o}} 386 / 2012$, que regulamenta a lei que instituiu a referida taxa e previa reduções das alíquotas incidentes, revogou tais reduções, acarretando um aumento da exigência original e representa um acréscimo na arrecadação estatal.

Tal alteração intensificou ainda mais o debate em relação à constitucionalidade do referido tributo, visto que, desde 2012 tramita no Supremo Tribunal Federal uma Ação Direta de Inconstitucionalidade - ADI em face da Lei $n^{\circ} 7.591 / 11$, proposta pela Confederação Nacional das Indústrias - CNI.

\section{A ADI 4.786 SOBRE A LEI No 7.591/11}

Conforme citado em tópico supra, a ADI n 4.786, distribuída em 31.05.2012, busca a declarar a inconstitucionalidade da Lei ${ }^{\circ}$ 7.591/11 que instituiu a Taxa de Fiscalização de Recursos Minerários (TFRM) no Pará.

De acordo com o que propõe a ADI n 4.786, não faltam inconstitucionalidades na lei atacada, mas destaca-se, em primeiro lugar, o uso da rubrica de "taxa" para criar tributo:

"O tipo jurídico taxa não guarda qualquer semelhança com a exação criada pela lei atacada, pois taxa é tributo contraprestacional, estabelecido sob a lógica do custo benefício, enquanto o tributo em questão foi moldado para gerar arrecadação exorbitante em relação à atuação estatal que pretende apontar."

Além de alegar esse possível vício de inconstitucionalidade, afirmando que tal cobrança ocorre sobre o "disfarce de taxa", a ADI propõe como um segundo vício que a tonelada do minério não possui relação com a base de cálculo própria de taxa, visto que, mede a atividade estatal, específica e divisível, relacionada ao contribuinte, sendo uma base de cálculo própria de imposto.

Em terceiro lugar, a ADI trata que a competência fiscalizatória do art. 23, XI, da Constituição Federal não constitui poder de polícia que permita a instituição de taxa, e aduz que não há, no caso em questão, poder de polícia que legitime a instituição de taxa, o que também levaria à declaração de inconstitucionalidade dos artigos $1^{\circ}$ a 12 da Lei 7.591/2011. 
A ADI traz como um quarto vício de inconstitucionalidade a falta de competência do Estado do Pará para legislar e para exercer poder de polícia sobre as atividades mineiras, alegando ser de competência do IBAMA, autarquia federal, para exercer o poder de polícia ambiental.

E, por fim, a ADI aduz que a taxa representa onerosidade excessiva para alguns minerais e o instrumento para mitigar isso (art. $6^{\circ}, \S 3$, da Lei 7.591/11) viola a legalidade tributária. Nesse sentido, é afirmado que há onerosidade excessiva global, visto que, a taxa se destina a arrecadação de recurso desproporcional à despesas correlata, revelando-se como imposto. E que há também a onerosidade excessiva individual, revelando-se como efeito confiscatório sobre determinadas atividades minerais.

Assim, de acordo com a ADI em comento, os vícios de constitucionalidade trazidos referem-se aos doze primeiros artigos da Lei $\mathrm{n}^{\circ} 7.591 / 11$, sendo os demais artigos e o decreto 386/2012 inconstitucionais por arrastamentos, visto que, as disposições não possuem sentido sem a taxa.

Em análise de jurisprudências atuais, percebe-se que recentes julgamentos da Suprema Corte criaram precedentes que podem ser desfavoráveis e um possivelmente favorável ao julgamento da TFRM do Pará.

Observa-se, primeiramente, os recentes julgamentos da Taxa Ambiental das Atividades de Pesquisa, Lavra, Exploração e Produção de Petróleo e Gás - TFPG. Em abril de 2020, o STF declarou inconstitucional a TFPG do Rio de Janeiro, nas ADIs $n^{\circ}$ 5480/RJ e 5512/RJ, com o fundamento de que a base de cálculo da taxa que é baseada no barril de petróleo é desproporcional com os custos da fiscalização.

Secundariamente, em fevereiro de 2021, o Plenário do STF julgou procedente o pedido formulado na ADI $\mathrm{n}^{\circ}$ 5.374, acerca da aplicabilidade da Taxa de Controle, Acompanhamento e Fiscalização das Atividades de Exploração e Aproveitamento de Recursos Hídricos - TFRH. O Plenário conclui que é legítima a criação de taxas de fiscalização pelos Estados, nos limites da competência comum dos entes para a proteção do meio ambiente atribuída pela Constituição. Entretanto, finalizou julgando inconstitucional a taxa em questão, em razão da incongruência entre o valor cobrado e o custo da atividade estatal oferecida.

Em sentido contrário, ocorreu o início do julgamento da ADI no 4785/MG, no qual se discute a TFRM do estado de Minas Gerais, que ocorreu em outubro de 2020 e foi 
retirado do julgamento virtual, mas, até o momento, o Supremo Tribunal Federal - STF vinha adotando outro caminho na sua decisão.

Antes de ser retirada do julgamento virtual, além do Ministro Relator Edson Fachin, outros quatro ministros votavam em favor da constitucionalidade da taxa, afirmando que havia razoabilidade entre a quantidade de minério extraído e o dispêndio de recursos públicos com a fiscalização dos contribuintes.

Diante disso, observa-se que, em outras oportunidades, o STF se pronunciou sobre a validade de taxas instituídas pelo exercício do poder de polícia pelos estados, e percebe-se que as recentes decisões proferidas vêm caminhando no sentido de reconhecer a inconstitucionalidade. No entanto, o início do julgamento da TFRM de Minas Gerais se mostrou diferente, e o caso agora será reiniciado em sessão tele presencial, a fim de que haja amplo debate entre os Ministros.

Com o reinício do julgamento, se a Corte decidir em consonância com as decisões já estabelecidas, há a possibilidade de vermos declarada a inconstitucionalidade da Taxa Minerária do Estado de Minas Gerais, que, consequentemente, será mais um forte precedente para uma eventual declaração de inconstitucionalidade da Taxa Minerária do Estado do Pará.

Diante disso, levando em consideração os precedentes já fixados, como o da TFGP e da TFRH explanadas anteriormente, o problema das taxas tange à base de cálculo e o valor cobrado, e não sobre a competência do ente para instituir ou a existência da taxa em si. Por consequência, percebe-se que a problemática seja em relação à questão legislativa, em razão do valor fixado quanto a cobrança da taxa.

Por seguinte, cabe relacionar o pensamento firmado no parágrafo supra com a filosofia pragmática de Richard Posner, que afirma que, eventualmente, a questão não será respondida no judiciário, mas em outra esfera, e no caso em análise, seria o legislativo. Vejamos:

Os juízes pragmáticos, diz Posner (2007a, p. 301), ao decidirem seus casos, são encarregados de criarem o direito prevendo as consequências de suas decisões [...] $\mathrm{O}$ importante é que o direito é algo que autorizou pessoas, em especial juízes, advogados e legisladores, a fazer, e não uma caixa cuja tampa abrem quando surge uma questão jurídica (DIAS; LEITE, 2016, p. 160). 
Nesse sentido, Posner traz o entendimento de que a norma jurídica ou a decisão judicial dela advinda precisam estar atentas para as suas consequências práticas, de modo a garantir a sua eficiência perante a sociedade.

Consequentemente, vale lembrar as recentes as recentes tragédias ocorridas em solo mineiro, decorrentes da ausência de fiscalização efetivas e políticas públicas no setor, como o caso ocorrido em Mariana/MG, a partir do rompimento da barragem de Fundão, em 2015, e a consequente paralisação das atividades da empresa mineradora Samarco.

Assim, diante de uma atividade que pode gerar tantas externalidades negativas e de uma possível inconstitucionalidade da Taxa Minerária do Estado do Pará, que é cobrada diante do serviço de fiscalização realizada pelo ente, questiona-se como seria realizada uma eficiente fiscalização sem a taxa e quem financiaria os custos de tal atividade prestada pelo Estado.

\section{OS POSSÍVEIS REFLEXOS DE UMA EVENTUAL (IN)CONSTITUCIONALIDADE DA TAXA MINERÁRIA NO ESTADO DO PARÁ}

Sabe-se que a mineração é uma atividade provocadora de possíveis problemas socioambientais, que se esgota juntamente com as reservas minerais, visto que estas são finitas. Nesse sentido, há que se falar que os recursos provenientes dela, também variam de acordo com a vida útil das reservas.

De acordo com Andrews-Speed e Rogers (1999, p. 221), desde 1970 e 1980, no campo da tributação de minerais, são empregados esforços de acadêmicos e de consultores para encontrar maneiras eficazes de dividir a renda econômica decorrente de projetos de mineração entre o investidor e o estado anfitrião, de forma que os interesses de ambos fossem satisfeitos.

Nesse sentido, encontra-se a Taxa Minerária que, conforme já mencionado, é a taxa cobrada referente à fiscalização prestada à atividade minerária pelo Estado, aqui em análise o Pará.

De acordo com Maurílio Monteiro (2005, p. 188), a exploração mineral teve início no Pará a partir de 1974, com a implementação do Projeto de Pólos Agropecuários e Agrominerais da Amazônia - Polamazônia, criado pelo Governo Federal, que buscava a implementação de pólos de desenvolvimento na Amazônia brasileira. Alguns dos pólos que 
integram o referido projeto eram paraenses, como Carajás, localizado em Parauapebas com a extração do minério de ferro, e Trombetas, no município de Oriximiná com a bauxita.

Atualmente, o Estado do Pará tem como a base de sua economia a exportação mineral, que representou em $88 \%$ das exportações totais do Estado em 2018, de acordo com o Anuário Mineral do Pará de 2019, produzido pelo Sindicato das Indústrias Minerais do Estado do Pará - Simineral.

Diante disso, resta evidente a importância econômica de tal atividade para o estado. Entretanto, vale lembrar que se trata de uma atividade que explora um recurso finito, e, por consequência, a atividade e os recursos provenientes dela só se manterão enquanto houver minério no subsolo paraense.

Sendo assim, é indubitável a necessidade de uma fiscalização efetiva, para que as leis sejam aplicadas e a degradação ambiental não ocorra. Nesse sentido, Ives Grandra Martins (2012, p. 424), em um parecer dado sobre a constitucionalidade da Taxa Mineral, afirma que:

Quem fiscaliza, quem acompanha, quem autoriza, à evidência, tem custos, no exercício de sua tarefa protetora da comunidade que o poder de polícia encerra, razão pela qual pode exigir, para fazer frente a eles - isto é, à atividade de fiscalização, acompanhamento e autorização - taxa correspondente ao serviço a ser prestado.

Nesse sentido, a Taxa Minerária faz-se necessária para o Estado do Pará, um estado essencialmente exportador de minérios, visto que, visa minimizar os impactos negativos gerados pela mineração no Estado. E, de acordo com Andrews-Speed e Rogers (1999, p. 222) a tributação possui um papel importante para reabilitação de minas, diante das externalidades negativas geradas por tal atividade.

Em análise ao Projeto de Lei de Diretrizes Orçamentárias LDO de 2022 do Estado do Pará, tem-se como risco fiscal o trâmite processual da ADI 4786, cuja decisão por uma eventual inconstitucionalidade poderá impactar em R \$ 500.000.000 (quinhentos milhões de reais) na arrecadação do Estado.

Ademais, o documento também prevê uma arrecadação de $\mathrm{R} \$$ 562.190.051 (quinhentos e sessenta e dois milhões, cento e noventa mil e cinquenta e um reais) para o ano de 2021, com base no que foi arrecadado em 2020, acrescidas de estimativas de variação do IPCA (Índice Nacional de Preços ao Consumidor Amplo).

De acordo com o Projeto, uma das metas e prioridades do Estado é fomentar e promover o uso sustentável dos recursos ambientais, a partir da implementação de núcleos 
regionais da Secretaria de Estado de Meio Ambiente e Sustentabilidade (SEMAS) em diversos municípios, aumentando, assim, a fiscalização nas regiões.

Conforme dispõe o art. 3, parágrafo único, inciso II, da Lei 7.591/11, que estabelece a Taxa Minerária, a Secretaria de Estado da Fazenda (SEFA), a Secretaria de Estado de Meio Ambiente (SEMA) e a Secretaria de Estado de Ciência, Tecnologia e Inovação (SECTI), apoiam, de modo operacional, a Secretaria de Estado de Indústria, Comércio e Mineração - SEICOM, quem exercer o poder de polícia no estado.

Cabe mencionar que, atualmente, a SECTI se chama SECTET - Secretaria de Estado de Ciência, Tecnologia e Educação Profissional e Tecnológica, e, com a extinção da SEICOM, a SECTET assume suas atribuições, direitos e obrigações, conforme o histórico disponibilizado no sito eletrônico desta.

Juntas, essas secretarias, tiveram uma despesa total avaliada em R \$ 737.457.520 (setecentos e trinta e sete milhões, quatrocentos e cinquenta e sente mil e quinhentos e vinte reais), de acordo com a Lei Orçamentaria Anual de 2021 (Lei n 9.160/21), que estimou e fixou a despesa do Estado para o ano de 2021.

Nesse sentido, entende-se que muitos são os custos gerados para que haja uma atividade fiscalizatória eficiente por parte do Estado, visto que, a implementação de diversos núcleos como os supracitados são financiados pelo ente.

Por seguinte, os reflexos de uma eventual inconstitucionalidade da taxa minerária, entende-se que a fiscalização restaria frustrada sem a previsão de tal financiamento.

Além disso, seria menos um recurso tributário que o Estado deixa de arrecadar, visto que, o Pará como maior exportador de minério do Brasil não arrecada o Imposto sobre Circulação de Mercadorias e Serviços - ICMS por conta da vigência da Lei Complementar $n^{\circ}$ 87/96, conhecida como Lei Kandir, cujo conteúdo se cristalizou na PEC no 42, de 2003, que isenta do recolhimento de ICMS produtos básicos e semielaborados, como é o caso dos minérios.

Desse modo, há que se falar nessa falta de instrumentos para o desenvolvimento sustentável local e o bem estar da sociedade, visto que, o Pará, como já demonstrado, é o maior exportador de minério da federação, ao passo que possui o povo com IDHM abaixo da média da região norte, de acordo com dados do Instituto Brasileiro de Geografia e Estatística - IBGE.

De acordo com Veiga (2010) o termo "desenvolvimento sustentável" remonta à ideia de que a humanidade pode atender às suas necessidades materiais sem comprometer a 
capacidade das próximas gerações de fazerem o mesmo. O pensamento do autor faz referência ao princípio da equidade geracional, o qual visa não esgotar para as futuras gerações as possibilidades que se têm hoje.

Eis que cabe analisar a questão puramente ambiental, visto que os recursos minerais são classificados como recursos naturais não-renováveis, isto é, são encontrados em formas de reservas e são finitos. Dessa forma, a natureza não é capaz de regenerá-los.

Ademais, o extrativismo mineral tem como importante característica a alteração drástica no ambiente em que é realizado, por isso a análise central deve ocorrer para compreender até que ponto há a contribuição da atividade extrativista mineral para o desenvolvimento local.

Nesse sentido, a Taxa é essencial para a fiscalização de uma atividade causadora de diversas alterações ambientais, muitas vezes, classificadas como desastres ambientais, quando atingem de forma intensa a população e o seu entorno. Logo, a taxa muito pode contribuir para que se alcance um desenvolvimento sustentável regional, a partir de tal fiscalização e fazendo com que as empresas internalizem as externalidades negativas geradas pela exploração mineral.

Assim, um estado que arrecada mais de R \$ 500.000.000 (quinhentos milhões de reais) a título de taxa, terá esse recurso suprimido se a Taxa Minerária for declarada inconstitucional, interferindo nas metas do Estado, em relação à implementação de unidades da SEMAS, dificultando, de modo geral, a fiscalização e, por consequência, inviabilizando o desejável desenvolvimento sustentável local e o bem estar social.

Além disso, ressalta-se que, sem a TFRM, que remunera a atividade de fiscalização, o Estado corre o risco de ter em seu território um potencial efeito desastroso da mineração, como o mencionado em Mariana/MG, dado que, a exploração mineral traz consigo os problemas ambientais, e sem a devida fiscalização eles são mais suscetíveis de ocorrerem.

\section{CONSIDERAÇÕES FINAIS}

Tendo em vista o contexto histórico da mineração, os danos socioambientais causados decorrente da exploração da atividade, a sua característica de finitude e a falta de desenvolvimento local, o artigo buscou demonstrar em que medida a possível declaração de inconstitucionalidade da Taxa Minerária afetaria o Estado do Pará. 
A partir da análise do Projeto de Lei de Diretrizes Orçamentárias LDO de 2022 do Estado do Pará, evidencia que a renda proveniente da TFRM possui um valor vultuoso e que é arrecadado pelos cofres públicos do Estado, possuindo um significado importante para o desenvolvimento local e o bem estar da sociedade, visto que, apesar do ente ser a unidade da federação com maior exportação de minério, demonstrou-se que tal desenvolvimento ainda é insuficiente quando este é comparado aos demais estados da região norte.

De acordo com o referido Projeto de LDO há uma preocupação com o trâmite processual da ADI 4786, cuja decisão por uma eventual inconstitucionalidade poderá impactar em R\$ 500.000.000 (quinhentos milhões de reais) na arrecadação do Estado. Tal preocupação é classificada como risco fiscal, pois há uma relação estreita entre a importância dos recursos minerais e o financiamento para o Estado, para que não ocorra de o desenvolvimento ser tornar exaurível junto ao recurso.

Ademais, a falta da arrecadação da TFRM impactará diretamente no orçamento do Estado, dado que ficou demonstrado que as Secretarias Estaduais, responsáveis pela fiscalização, consomem um valor exorbitante para que se mantenham em pleno funcionamento, conforme constatado na Lei Orçamentaria Anual de 2021.

$\mathrm{O}$ artigo mostrou, através de dados, a importância do montante arrecadado, e como a possível inconstitucionalidade impactaria as metas e prioridades do Estado, dispostas no Projeto de Lei de Diretrizes Orçamentárias para o ano de 2022, visto que, o Estado exporta suas riquezas, não havendo a preocupação por partes das empresas em investirem na verticalização da produção mineral aqui no Estado, levando o minério bruto e deixando para trás todos os problemas sociais, ambientais e econômicos causados pela atividade.

Também deve ser levado em consideração quanto o Pará já perdeu de Imposto sobre Operações relativas à Circulação de Mercadorias e Prestação de Serviços (ICMS) sobre as exportações destes minérios, em razão as Lei Kandir.

Desse modo, a partir de uma eventual declaração de inconstitucionalidade da Taxa Minerária, diante da ADI 4786, o Estado do Pará perderá um montante expressivo. E, sem viabilidade econômica, não será possível proceder uma fiscalização efetiva em todo o estado, restando comprometido o processo de desenvolvimento sustentável local e o alcance do bem estar social, visto que, o ente terá menos um recurso arrecadado a partir da mineração, uma atividade temporária e tão importante para a região. 
Além disso, vale ressaltar que, sem o financiamento da devida fiscalização, os municípios mineradores ficarão mais vulneráveis aos possíveis efeitos desastrosos causados pela atividade minerária.

\section{REFERÊNCIAS}

ANDREWS-SPEED, Philip; ROGERS, Christopher D. Mining taxation issues for the future. Resources Policy 25, 1999, 221-227. Disponível em: https://www.researchgate.net/publication/222852748. Acesso em: 15 jun. 2021.

Assembleia Geral da ONU. Declaração sobre o Direito ao Desenvolvimento. Resolução 41/128 da Assembleia Geral, de 4 de dezembro de 1986. Disponível em: https://www.un.org/en/events/righttodevelopment/declaration.shtml. Acesso em: 08 jun. 2021.

ATHIAS, Daniel Tobias. Regulação e royalties de minério e petróleo: análise comparativa Brasil e Estados Unidos. São Paulo: D’Plácido Editora. 1. ed., 2020.

BRASIL. Constituição da República Federativa do Brasil. Promulgada em 5 de outubro de 1988. Brasília: DF. Disponível em:

http://www.planalto.gov.br/ccivil_03/constituicao/constituicao.htm. Acesso em: 04 jun. 2021

BRASIL. Código Tributário Nacional. Lei no 5.172 de outubro de 1966. Disponível em: http://www.planalto.gov.br/ccivil_03/leis/15172compilado.htm. Acesso em: 04 jun. 2021.

BRASIL. Supremo Tribunal Federal. Ação Direta De Inconstitucionalidade $\mathbf{N}^{\circ} \mathbf{4 7 8 5}$. Relator: Min. Edson Fachin. Disponível em: http://portal.stf.jus.br/processos/detalhe.asp?incidente=4252832. Acesso em: 28 jun. 2021.

BRASIL. Supremo Tribunal Federal. Ação Direta De Inconstitucionalidade $\mathbf{N}^{0} 5480$. Relator: Min. Alexandre de Moraes. Disponível em:

http://portal.stf.jus.br/processos/detalhe.asp?incidente=4936179. Acesso em: 28 jun. 2021.

BRASIL. Supremo Tribunal Federal. Ação Direta De Inconstitucionalidade No 5512. Relator: Min. Alexandre de Moraes. Disponível em:

http://portal.stf.jus.br/processos/detalhe.asp?incidente=4973482. Acesso em: 28 jun. 2021.

BRASIL. Supremo Tribunal Federal. Ação Direta De Inconstitucionalidade No 4786.

Relator: Min. Nunes Marques. Disponível em:

https://redir.stf.jus.br/paginadorpub/paginador.jsp?docTP=TP\&docID=2137920\&prcID=4252 998\&ad=s\#. Acesso em: 10 jun. 2021.

BRASIL. Supremo Tribunal Federal. Ação Direta De Inconstitucionalidade $\mathbf{N}^{0} 5374$. Relator: Min. Roberto Barroso. Disponível em:

http://portal.stf.jus.br/processos/detalhe.asp?incidente=4838097. Acesso em: 28 jun. 2021. 
CARVALHO FILHO, J. S. Poder de Polícia. In: CARVALHO FILHO, J. S. Manual de Direito Administrativo, cap.III. 15 ed. Rio de Janeiro: Lumen Juris, 2006, p.63-83.

DA SILVA, Fernanda Alen Gonçalves. Romper com a "maldição dos recursos minerais": um caminho a ser trilhado. Belo Horizonte/MG, 2017. Disponível em:

<https://repositorio.ufmg.br/handle/1843/BUBD-AW6MUA>. Acesso em: 16 jun. 2021.

DE CARVALHO, Luísa Mendonça Albergaria. A intervenção estatal via exações (TRFM e CFEM) sob a perspectiva da proteção do meio ambiente na atividade minerária e o “Caso Samarco". Belo Horizonte/MG, 2017. Disponível em: https://repositorio.fumec.br/xmlui/handle/123456789/639. Acesso em: 10 jun. 2021.

DIAS, J. C.; LEITE, G. N. A decisão judicial nos casos difíceis: uma análise a partir do debate entre Dworkin e Posner. Teorias do Direito e Realismo Jurídico, Curitiba, v. 2, n. 2, p. 149-169, jul./dez. 2016.

ENRÍQUEZ, Maria Amélia. LOUREIRO, João Gustavo Gouveia. NEVES, Marjorie Barros. FERRAZ, Lucas Paiva. Contradições do desenvolvimento e o uso da CFEM em Canaã dos Carajás (PA). Rio de Janeiro: Instituto Brasileiro de Análises Sociais e Econômicas, 2018. Disponível em: https://ibase.br/pt/noticias/uso-da-cfem-em-canaa-dos-carajas-pa-erevelado-em-pesquisa/ Acesso em: 01 maio 2021.

IBGE - Instituto Brasileiro de Geografia e Estatística. Índice de Desenvolvimento Humano (IDH). Rio de Janeiro, 2010. Disponível em:

https://cidades.ibge.gov.br/brasil/pa/pesquisa/37/0?tipo=cartograma. Acesso em: 16 jun. 2021.

MARTINS, Ives Granda da Silva. Parecer sobre a TFRM do Pará. Revista dos Tribunais, vol. 919, maio/2012, p. 403-439. Disponível em: https://gandramartins.adv.br/parecer/taxade-fiscalizacao-mineral-do-estado-do-para-exercicio-de-competencia-impositiva-outorgadapela-constituicao-federal-artigos-23-inciso-xi-e-145-inciso-ii-exacao-constitucional-parecer/. Acesso em: 29 jun. 2021.

MEIRELLES, H. L. Direito Administrativo Brasileiro. 26 ed. São Paulo: Malheiros, 2001.

MONTEIRO, Maurílio de Abreu. Meio século de mineração industrial na Amazônia e suas implicações para o desenvolvimento regional. Estudos Avançados v. 19 n. 53, p. 187207, 2005. Disponível em: http://www.scielo.br/pdf/ea/v19n53/24088.pdf. Acesso em 30 jun. 2021.

PARÁ. Decreto no 1.353, de 04/03/2021. Altera o Decreto no 386, de 23 de março de 2012 que regulamenta a Lei $\mathrm{n}^{\circ} 7.591$, de 28 de dezembro de 2011. Disponível em: https://www.legisweb.com.br/legislacao/?id=410400. Acesso em: 03 jun. 2021.

PARÁ. Lei Ordinária no 7.591, de 28 de dezembro de 2011. Institui a Taxa de Controle, Acompanhamento e Fiscalização das Atividades de Pesquisa, Lavra, Exploração e Aproveitamento de Recursos Minerários - TFRM e o Cadastro Estadual de Controle, 
Acompanhamento e Fiscalização das Atividades de Pesquisa, Lavra, Exploração e Aproveitamento de Recursos Minerários - CERM. Disponível em:

https://www.semas.pa.gov.br/legislacao/files/pdf/312.pdf. Acesso em: 03 jun. 2021.

PARÁ. Lei Ordinária Anual no 9.160, de 06 de janeiro de 2021. Estima a receita e fixa a despesa do Estado do Pará para o exercício financeiro de 2021. Disponível em:

http://seplad.pa.gov.br/wp-content/uploads/2021/01/Lei-9160-loa-2021-ASSINADA-1.pdf. Acesso em: 30 jun. 2021.

PARÁ. Projeto de Lei de Diretrizes Orçamentárias de 2022. Dispõe sobre as diretrizes orçamentárias para o exercício financeiro de 2022. Disponível em:

https://seplad.pa.gov.br/wp-content/uploads/2021/05/Projeto-de-Lei-LDO-2022.pdf. Acesso em: 28 jun. 2021.

PARÁ. Secretaria de Ciência, Tecnologia e Educação Superior, Profissional e Tecnologia. Histórico. Disponível em: http://www.sectet.pa.gov.br/audiovisual/basic-page/histórico.

Acesso em: 30 jun. 2021.

SINDICATO DAS INDÚSTRIAS MINERAIS DO ESTADO DO PARÁ - SIMINERAL. $8^{\circ}$ Anuário Mineral do Pará (2019). Disponível em: https://simineral.org.br/pdf/anuarios/8desktop_pt-br.pdf. Acesso em: 29 jun. 2021

VEIGA, José Eli da, Desenvolvimento Sustentável: o desafio no século XXI. Rio de Janeiro: Garamond, 2010. 